\title{
Research of Physical Education and Reform of Vocational Colleges Based on Occupation Ability Angle of View
}

\author{
Wei zeyong ${ }^{1, a}$ \\ ${ }^{1}$ Jiujiang Vocational University, Jiujiang Jiangxi 332000, China \\ a869561247@qq.com
}

Keyword: vocational education; occupation ability; curriculum reform

\begin{abstract}
The higher vocational education is an important base of professional and technical personnel training in China, and it plays an important role in the training of professional and technical personnel in china. With the application of occupation oriented teaching development, modern vocational education work should follow the teaching contents and requirements for the corresponding reform. The teaching quality of physical education in vocational colleges is improved. From the perspective of sports features, the training of occupation ability is researched. We believe that sports colleges have instrumental value as professional curriculum, and it has the cultural value to cultivate the professional core ability. The theory of sports teaching mode in higher vocational education is improved, and the research result has good practical significance the in the implementation of physical education teaching reform.
\end{abstract}

\section{Introduction}

The teaching goal of modern higher vocational colleges is determined as cultivation of professional and technical personnel, the modern higher vocational colleges education takes the orientation as a professional and technical personnel training in higher vocational teaching, the occupation ability is taken as the orientation, the higher vocational teaching needs to cultivate the students with good physical quality[1], the cultivation of good physical strength requires students have occupation and physical quality through vocational education, it can provide a lot of professional and technical personnel for modern economic development, the overall quality of students is improved. The comprehensive ability of students is obtained, and it provides good foundation for improving the working ability[2].

\section{Investigation of present situation of occupation ability cultivation in physical education of higher vocational colleges}

The survey started in September 2013, in the new school year and at the first semester, students in school of Shaanxi traffic Career Academy is taken as the objects, 100 students are taken as the sample, 100 questionnaires are recycled, of which 98 questionnaires are effective questionnaire, the efficiency rate is $98 \%[3]$.

After the analysis of investigation results, currently, for the students in Shaanxi traffic Career Academy, the understanding of the occupation ability is still in the fuzzy state, very understanding and better understanding of the students is $6 \%$ and $26 \%$, the students who don't know and don't understand the occupation ability reaches $34 \%$. The distribution diagram is shown in Figure1.

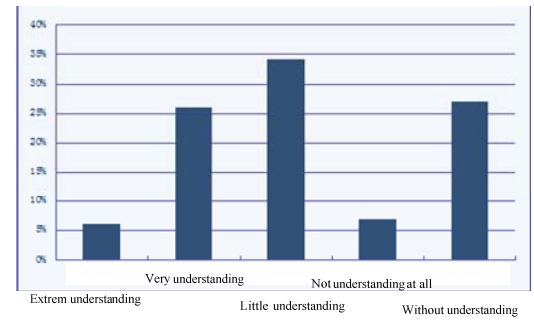

Figure 1. Understanding distribution of occupation ability 
Compared to understanding of occupation ability, the higher vocational college students have different views in the understanding of importance of occupation ability[4 6], no one think that the occupation ability is not important, 92\% of the students think that the occupation ability is important. This also shows that the higher vocational students have very clear positioning and occupation ability understanding. The result of data statistic is shown in Figure 2.

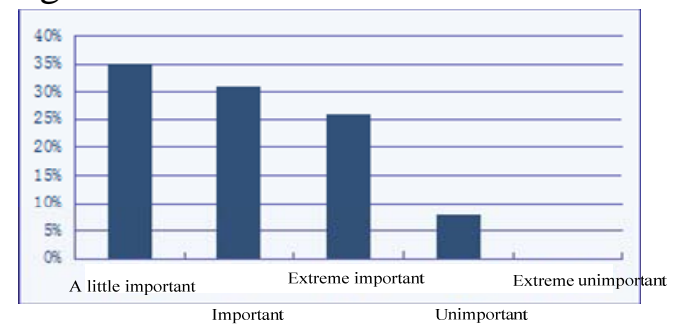

Figure 2 Importance recognition of occupation ability

With the occupation ability cultivation, the employment ability is improved. For the investigation of occupation ability to improve the employment ability, more than $60 \%$ of the students think it is important and very important, only $8 \%$ of the students think that culture occupation ability to enhance the employment ability is not important. The result of data statistic is shown in Figure 3.

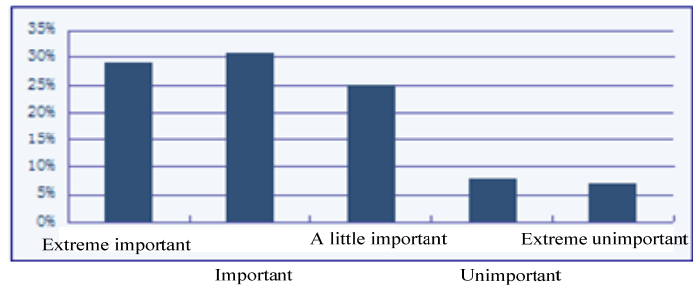

Fig. 3 Occupation ability training is very important for promoting the employment ability

As far as we know, physical education is the foundation part of a full-scale development of education in Higher Vocational Colleges, to realize the training goal of higher vocational education, so it plays an important role in training specialized personnel with all-round development. Practice has proved, the higher vocational colleges can make the students master physical knowledge and skill by means of physical teaching. It can promote them to develop good habits of regular physical exercise, increasing physical fitness, and cultivating the training ability. It promotes the development of comprehensive quality, and it also can cultivate their moral character and moral fashion.

With the application of modern science and technology, front-line operators need overall quality in physical ability and professional ability, and the physical education must be reformed, according to the work demand after graduation, the teaching contents of college physical education must be adjusted. In order to cultivate students' good physique and psychological quality, the physical education and reform is researched. The NC professional graduate students are taken as an example, and it needs to stand in front of CNC machine tool and control the operation of equipment in work, the work time is in 8 hours or more than 8 hours. The physical overhead is big, and it has higher strength and endurance requirements. This requires in the sports teaching the related training for their occupation demand, and provides good foundation for the students’ work.

\section{Problems and reasons of occupation ability training of Vocational Colleges PE Teaching}

\section{A.The teaching idea has not been fundamentally changed}

Physical education of higher occupation education task aim is not specific, and the object of higher vocational colleges is to improve students' occupation skill, it is taken around for improving professional skills as the center, to form their own system of knowledge, skill system, and quality system. Today, professional and skill dual education are taken in higher vocational colleges, teaching students to master professional theoretical knowledge and practical ability, the ability for self long-term development is formed. At present, due to a variety of realistic factors, the purpose of 
physical education gradually become utilitarian, the physical education is ignored, while ignoring the practical skills of sports. Therefore, graduates cannot meet the needs of the work issues with increasingly pressure, which completely opposite to the cultivation aim

So far, some old teachers with old concepts still cannot correct the traditional educational ideas, make the PE teaching of higher occupation education is far from the teaching goal as "take the market demand as the guidance, and improve their comprehensive skills". On the contrary, the theoretical knowledge teaching and professional knowledge system construction are taken as the central task of teaching work. For a long time, occupation practice ability of students has been neglected, although the relevant professional training and classroom activities is also difficult to make up, teachers have replaced the students become the main body of teaching

\section{B.Physical education in Higher Vocational Colleges lacks pertinence without effectiveness and technical characteristics}

The reform of the higher occupation education defines delivery can adapt to the needs of the skilled talents job occupation and occupation practice, and it is the essential requirement of higher vocational education and the ultimate goal for employers. However, the sports teaching in the current higher vocational institute, the teaching content and professional are independent, but also the lack of professional background, this also caused a serious disconnect between and practice of sports in higher vocational education, occupation of the teaching content is not strong. Based on the teaching guiding ideology of higher occupation career training, the skills of the students is enhanced, vocational education should be carried out to promote the student's occupation ability as the main target, ordinary sports teaching guidance information previously used should be updated.

\section{C.Physical education teaching time is serious insufficient}

The reform of the higher occupation education is carried out, and the particularity of "multi wheel" teaching practice has a great impact on physical education teaching reform. The higher occupation schools have occupation education reform theory and practice teaching, PE class number cannot be guaranteed, which seriously affected the normal physical education teaching.

\section{D.Sports curriculum content does not adapt to the physical and mental development of students}

The PE content is far away from the real life of students, it ignores the cultivation of students' interest in learning and physical ability, it has disjointed with lifelong physical education. The implementation of Physical Education Course is taken the teacher as center, competition sports are the center, so we should develop physical quality as the center, to develop students' subjectivity and creativity.

\section{E. Evaluation of physical education too much emphasis on physical fitness and sports skills of students.}

The current physical education curriculum evaluation standards are sole, the absolute evaluation standard is taken, and the effectiveness is bad. Physical education is different from other courses, the physical quality, grasp the technical abilities are influenced by genetic factors and objective factors. The current evaluation method is composed of basic theory, attendance, and so on. An uniformed standard and unified project need be constructed.

\section{Strategy of physical education reform}

At this stage, physical education should start from changing educational ideas, and the successful experience from abroad is used to strengthen the theoretical research, the important role of physical education for students occupation ability is made clear, the perfect fusion method is seek. In the exploration of reform, the connotation of sports education deep in the reform is researched, and actively to examine physical education from the perspective of occupation ability. Teaching, teaching reform and course construction are reformed. A suitable sports teaching platform with occupation ability cultivation of Higher Vocational Students is established. 
A.Physical education in higher vocational education should embody the professional characteristics, develop occupation physical.

In physical education teaching oriented by occupation ability, the sports teaching mode should be reformed, so as to promote the interests of students occupation corresponding sports culture. The modern multimedia technology and teaching methods are used to promote the students' interest in sports and the cultivation, and the competitive games are used to verify its effect. The computer related major is taken as the example, in cycling teaching activities, variety of bicycle exercise modes are fused in the multimedia technology, with the demonstration and explanation, students may find suitable items for their own interest in sports of cycling, such as mountain bike, road cycling, cycling venues and techniques cycling. At the same time, through the multimedia technology, the action essentials are described in detail, the sport theoretical understanding and knowledge of students are improved effectively. It makes the foundation for the development of the sports.

\section{B.Develop students' good occupation quality in physical education curriculum}

Through the above analysis we can see, the teaching work of modern sports must improve physical quality of students to design the content of professional development, adapt the physical quality to student work requirements. . In the modern teaching of higher vocational education, higher vocational education should strengthen the sports teaching and research, the occupation development direction is specified for different professional, demonstrate the physical quality required for the different occupation. Higher vocational education should strengthen the sports teaching, the occupation development direction is designed for different professional. In order to design teaching contents scientifically, lay the foundation for the cultivation of students' physical quality, The modern PE Teaching in Higher Vocational Colleges develop occupation ability oriented teaching concept, the physical education teaching content is reformed. To promote physical fitness demand occupation of the students, a good foundation for the development of modern economy culture required for professional and technical personnel is established. It can promote the economic development of our country.

\section{Conclusions}

In modern higher vocational colleges, sports teaching activities should be aware of the importance of occupation as guidance for teaching reform. The sports teaching and Research Group takes analysis and argumentation of sports teaching reform, the professional curriculum, contents and teaching methods are changed. The reform of physical education curriculum improves physical quality training, and the students' interest in sports and the basic knowledge are cultivated. The occupation disease can be prevented with good sports habit.

\section{References}

[1] DENG Jing-sheng. The new view about reform of the method of pre-service teacher education practice under the background of new curriculum[J]. CAREER HORIZON, 2012, 8(9): 81-83.

[2] LIU Xu-dong. On Educational Practice Ability of Normal Students and the Reform of Education and Internship Program[J]. Contemporary Education and Culture, 2011, 3(2): 74-79.

[3] Yu Jia, Zhu Zhiqiang. Research On I-U-R Collaborative Innovation Based on Ecological Theory[J]. Bulletin of Science and Technology, 2013, 29(7): 225-230.

[4] WU Lan. Based on The Variety Constraint Model of Remote Education Database Query Optimization Algorithm[J]. Bulletin of Science and Technolog, 2013,1(29):155-160.

[5] IPCC.Climate Change 1995-The Second Scientific Assessment Report of the Intergovernmental Panel on ClimateChange. Working Group I to the Second Assessment Report of the IPCC . 1996

[6] AQF Advisory Board. RPLNational Principles. http://www.aqf.edu.au/rplnatprin.htm . 2007 